AperTO - Archivio Istituzionale Open Access dell'Università di Torino

\title{
A review of computational approaches detecting microRNAs involved in cancer
}

\section{This is the author's manuscript}

Original Citation:

Availability:

This version is available http://hdl.handle.net/2318/1633746

since 2017-05-15T00:08:03Z

Terms of use:

Open Access

Anyone can freely access the full text of works made available as "Open Access". Works made available under a Creative Commons license can be used according to the terms and conditions of said license. Use of all other works requires consent of the right holder (author or publisher) if not exempted from copyright protection by the applicable law. 
A review of computational approaches for the detection of micrornas involved in cancer

Laura Cantini ${ }^{1}$, Michele Caselle ${ }^{2}$, Antoine Forget ${ }^{3}$, Andrei Zinovyev ${ }^{1}$, Emmanuel Barillot $^{1}$, Loredana Martignetti ${ }^{1}$

${ }^{1}$ Institut Curie, INSERM U900, PSL Research University, Mines ParisTech, 26, rue d'Ulm, F-75248 Paris, France, ${ }^{2}$ Department of Physics, University of Torino and INFN, Via Pietro Giuria 1, 10125 Torino, Italy, ${ }^{3}$ Institut Curie, CNRS UMR 3306, INSERM U1005, Centre Universitaire, Batiment 110, 91405 Orsay, France

\section{TABLE OF CONTENTS}

1. Abstract

2. Introduction

3. Computational approaches to detect miRNAs involved in cancer onset and subtyping

3.1. Methods based on miRNA expression data

3.2. Methods based on mRNA expression data

3.3. Methods based on combined miRNA-mRNA expression data

3.4. Methods taking into account the miRNA-TF crosstalk

3.5. More recent integrative works considering also other data types: methylation, copy number and PAR-CLIP-based

3.6. Methods considering the miRNA-miRNA synergistic effect

4. Conclusions and perspectives

5. Acknowledgement

6. References

\section{ABSTRACT}

MicroRNAs (miRNAs) are small non-coding RNAs playing an essential role in gene expression regulation. Multiple studies have demonstrated that miRNAs are dysregulated in cancer initiation and progression, pointing out their potential as biomarkers for diagnosis, prognosis and response to treatment. With the introduction of high-throughput technologies several computational approaches have been proposed to identify cancer-associated miRNAs. Here, we present a systematic and comprehensive overview of the current knowledge concerning the computational detection of miRNAs involved in tumor onset and subtyping, with possible theranostic employment. An overview of the state of art in this field is thus proposed with the aim of supporting researchers, especially experimentalists and pathologists, in choosing the optimal approach for their case of study.

\section{INTRODUCTION}

For many years the search for cancer biomarkers focused primarily on alterations in the status and expression of protein-coding genes conferring a survival advantage to cancer cells (oncogenes) or preventing cancer progress (tumour suppressors).

The first evidence that, besides protein coding genes, non coding RNAs (ncRNAs) and in particular microRNAs (miRNAs) can act as either oncogenes (oncomiRs) or tumour suppressors was the identification of miR-15 and $m i R-16$ as potential cancer genes in the pathogenesis of chronic lymphocytic leukemia (CLL) (1). In more than half of CLL cases and in other malignancies, deletion of 13q14.3. was reported, suggesting the occurrence in this region of tumor suppressor genes involved in the initiation or progression of this disease. However, the identification of causal genes related to loss of 13q14.3. in CLL failed, until the discovery that the critical region contained two tightly linked miRNAs, miR-15a and miR-16-1, responsible of tumor suppression.

In the early 1990s miRNAs were discovered (2, 3) as small non-coding RNA molecules (approximately 22 nucleotides in length) that post-transcriptionally regulate gene expression by binding targets mRNAs and leading to inhibition of translation or mRNA degradation (4). MiRNA are transcribed from different genomic locations as long primary transcripts (pri-miRNA) by RNA polymerase (5). Frequently, to allow coordinated expression, some miRNAs are clustered in polycistronic transcripts. Once transcribed, the pri-miRNA is processed by the successive action of two enzymes, Drosha and Dicer, to generate the mature miRNA, recruited into an effector complex called RNA-induced silencing complex (RISC). In animals, the mature miRNA guides the RISC complex to the target mRNAs through imperfect base-pairing to multiple sites preferentially observed in 3'untranslated regions (UTRs). In the currently described binding model, Watson-Crick base-pairing to the 5' end of miRNAs, especially to the so-called "seed" that comprises nucleotides 2-7, is crucial for targeting (6).

MiRNA genes are frequently located in cancer susceptibility regions and at fragile sites, supporting their involvement in cancer disease (7). Since 2002, when miR-15/16 involvement in CLL was described, expression data from a large panel of cancer cell types have confirmed aberrant miRNA expression in a variety of cancer diseases (8-10). More recent experimental evidences suggest that specific miRNAs may also have a role beyond the cancer onset and directly participate in cancer invasiveness and metastasis $(11,12)$. In fact, miRNA profiles can distinguish not only between normal and cancerous tissue but they can also successfully classify different subtypes of a particular cancer $(13,14)$. Moreover, due to their small size, miRNAs 
are more stable than long mRNAs, allowing expression profiling from fixed tissues or other biological material. These results thus corroborate the interest in miRNAs as novel, minimally invasive and robust biomarkers. In the last years, the discovery of miRNAs in body fluids has opened the perspective to introduce miRNAs in clinics as biomarkers and putative therapeutic targets $(15,16)$.

Since miRNAs started to be largely studied, multiple reviews dealing with these small non coding RNAs in cancer have been proposed (17-19). Some of them provide an overview of the existing methods for miRNAs discovery (18). Some others take into account the different approaches for the prediction of miRNAs target transcripts (19). Finally, others are more centered on the medical aspects concerning microRNAs in cancer and they briefly report some examples of computational tools (17). Here we present a systematic and comprehensive overview of the current knowledge concerning the computational identification of miRNAs involved in cancer onset and subtyping, with possible theranostic employment. The aim of this review is thus to help researchers, especially experimentalists and pathologists, in choosing the optimal approach for their case of study. Indeed due to the complexity and heteregeneity of cancer diseases, computational approaches and system-oriented studies are becoming largely employed to complement some limitations of experimental studies (20). The description of the computational approaches is organized as follows: in the first part, we describe methods exploiting expression data from miRNAs and/or mRNAs. The second part is devoted to those methods that capture the effect of a joint miRNA-TF regulation. Then, some pipelines are introduced that make use of more recent types of genomic data such as PAR-CLIP data and methylation profiles. In the last part, more recent pipelines taking into account the miRNA-miRNA synergistic effect are described.

\section{COMPUTATIONAL APPROACHES TO DETECT MIRNAS INVOLVED IN CANCER ONSET AND SUBTYPING}

Following the discovery of the crucial role of miRNAs in cancer, computational methods for the identification of microRNAs potentially driver of cancer onset or subtyping have been proposed. Here, with the term miRNA driver we refer to a miRNA whose overexpression promotes the transition of a cell from the normal state to the cancerous one (cancer driver miRNA), or from a cancer subtype to another (cancer subtyping driver miRNA). Depending on the type of data that they employ, six main categories of approaches can be distinguished: (i) Methods based on miRNA expression data; (ii) Methods based on mRNA expression data; (iii) Methods based on combined miRNA-mRNA expression data; (iv) Methods taking into account the miRNA-TF crosstalk; (v) More recent integrative works considering also other data types; (vi) Methods considering the miRNAmiRNA synergistic effect. These six points are treated in detail in the sections below, a summary of the main computational approaches employed in the proposed algorithms is presented in Figure 1 and an overview of the available tools for each category is summarized in Table 1.

\subsection{Methods based on miRNA expression data}

The role of microRNAs in cancer started to be explored computationally when the first profiling methods, able to measure the expression pattern of all known miRNAs, were made available $(1,21-27)$. At the beginning, the bioinformatic studies employing these expression data were aimed at investigating whether miRNAs expression could be used to distinguish tumour from normal tissue (26). Interestingly, such works proved that miRNA expression profiles could be surprisingly informative even when no robust mRNA marker could be identified. As a consequence, their encouraging classification power and their number, lower than that of mRNAs, made them suitable as tumor biomarkers. Many researchers started to explore computationally the involvement of miRNAs in cancer onset and subtyping through the analysis of their expression data with statistical tests as Student's t-test (8, 28-30), Wilcoxon signed-rank test (31-33), ANOVA (32, 34, 35) and Significance Analysis of Microarrays (SAM) (8, 36).

The output of such analysis is generally composed of hundreds of miRNAs, some of which are likely to be false positives. However, a biomarker set should better be composed of only few molecules in order to be practically used in clinics, thus differential expression analysis alone is not sufficient and a second step of prioritization is mandatory. Multiple strategies were proposed to reduce the list of candidate microRNAs. When it was possible, microRNAs were ranked based on the number of similar studies in which they were found differentially expressed (37). This strategy led, for example, to the detection of miR21, miR-106b, miR-17, miR-18a and miR-20a as candidate diagnostic and/or prognostic biomarkers for gastric cancer. In other cases the functional consistency between the miRNA target genes and cancer-related genes was evaluated to quantify the association between miRNAs and the type of cancer under investigation (38). Data-driven approaches, based on the use of experimental measurements of other nature like epigenetics (39), or proteomics (40), or employing prior knowledge like networks $(41,42)$, were also employed for microRNA prioritization. This last strategy involves the reconstruction of an undirected weighted network, whose nodes and edges represent differentially expressed miRNAs and their correlations (when significant), respectively. In such a network, critical nodes were pointed out evaluating some centrality measures classically employed in network theory: degree, betweenness and clustering coefficient (43). Employing this approach, in (41) some candidate driver miRNAs in colorectal $(m i R-195, m i R-1280, m i R-140-3 p$ and $m i R-1246)$ and in pancreatic $(m i R-103, m i R-23 a$ and $m i R-15 b$ ) tumors were identified. Among them, some were already known to regulate key oncogenic processes. MiR-103 is associated with the TGF- $\beta$ signaling and thus it contributes in maintaining tissue homeostasis and it plays a crucial role in the suppression of the proliferation in cancer cells. MiR-23a is involved in the KRAS-mediated signaling. Finally, the overexpression of $m i R-1246$ had already been proved to decrease the induction of apoptosis. 
Given their ability to model the miRNA organization at a system-level, networks have been also employed alone to detect miRNA drivers. In some cases, following the procedure detailed above, a network whose nodes represent all the expressed microRNAs is reconstructed independently in tumor and normal tissue. Then the two obtained networks are compared to highlight cancer-associated microRNAs (44). Variants of the network reconstruction procedure were also explored, based on measures different from correlation (45), or combining miRNA expression with alternative sources of information as drug response and miRNA targets (46). In this last case, the approach led to the identification of 11 oncomiRs (e.g. miR-20a-5p, miR27a-3p, miR-29a-3p, and miR-146a-5p) biomarkers for metformin response in breast cancer. Finally, an approach completely independent from the aforementioned ones is PROGmiR (47), which selects biomarker miRNAs having a prognostic potential based on the Kaplan-Meier overall survival.

Overall, methods based on miRNA expression data can be easily used to identify miRNA biomarkers based on their differential expression between normal and cancer tissues. The association between miRNA and clinical data can also provide risk stratification of patients. A main advantage of miRNA in this context is that, as they are very stable in formalined tissues, retrospective or prospective studies can be performed on samples collected in a clinical setting. The main drawback of analysis using only miRNA data is the difficulty to define their functional consequences on disease progression with confidence.

\subsection{Methods based on mRNA expression data}

As described in the introduction, miRNAs act on the target mRNAs by translational silencing or mRNA degradation. Thus, it has been demonstrated that mRNA abundance for the majority of the targeted genes is somewhat affected by miRNAs $(48,49)$. Therefore the activity of a microRNA can also be predicted from mRNA expression data. Methods predicting miRNA activity using mRNA data are particularly useful as mRNA expression data are already available for virtually all diseases. The large availability of these data thus makes in silico studies predicting miRNA activity and their potential as biomarkers extremely powerful. Predictions based on such studies can have outcomes both for biologists studying a specific tumor or pathologists to assess new biomarkers.

All the algorithms that try to capture the dysregulation of a microRNA using only mRNA expression data generally explore the expression behavior of its targets obtained using only one predictive database (e.g. TargetScan, PITA, PicTar and miRanda). Some examples are Sigterms (50) and CORNA (51) that perform an mRNA differential expression analysis and then test whether the set of differentially expressed genes is enriched in predicted targets of a particular miRNA. Another tool is MirAct (52), which infers the regulatory effect of a miRNA via a two-step procedure. First, a score measuring the activity of a miRNA in a sample is obtained by comparing the expression levels of its non-targets with those of its targets. Second, the changes of miRNA activity across different classes of samples are investigated by comparing the scores across samples. Finally, miR-Path (53) is a recently developed R package to identify cancer driver microRNAs. The algorithm first identifies the targets of each microRNA, using more than one predictive database, then it ranks the microRNAs based on the number of cancer pathways that are enriched in their targets. The outputs of all these algorithms are strongly influenced by the huge amount of false positives and the unknown amount of false negatives produced by the currently available microRNA target prediction algorithms. On the contrary, CoMeTa (The Co-expression Meta-analysis of miRNA Targets) (54) is less affected by the number of false positive miRNA targets, given that it selects bona fide miRNA target genes by ranking them according to their degree of coexpression. Of particular note is the fact that miR-519d, miR-190 and miR-340, predicted by CoMeTa to regulate the TGF $\beta$ pathway, were functionally validated.

All these algorithms do not take into account miRNA expression data, thus the association between the miRNA and the mRNA expression levels is not evaluated, loosing a key information which could provide evidence for the regulatory relationship between the miRNA and its putative mRNA targets.

\subsection{Methods based on combined miRNA-mRNA expression data}

As pointed out in the previous section, the use of combined miRNA/mRNA expression data may be a timely strategy to study the regulatory relationship between a miRNA and its putative targets, permitting to achieve a higher precision in the identification of biomarker miRNAs in cancer and to asses their functional significance. Nowadays the study of combined miRNA/mRNA expression data is easy thanks to the multiple data types from hundreds of cancer patients that are collected in repositories such as Gene Expression Omnibus (GEO) (55), The Cancer Genome Atlas (TCGA, http://cancergenome.nih.gov) and the International Cancer Genome Consortium (ICGC (56)). Therefore, numerous procedures have been developed in the last years to infer miRNA activities from these data. Based on their final aim, these works can be divided into two main categories: (i) those interested in miRNA-mRNA couples and (ii) the microRNA-centered ones. The aim of the methodologies belonging to group (i) is the identification of co-expressed miRNA-mRNA couples whose behavior is altered in cancer. Such couples are generally identified by combining miRNA target prediction with miRNA/mRNA expression profiles correlation (57-61), or by more sophisticated approaches integrating miRNA/mRNA expression with sequence complementarity (62-64), or with other strategies capturing the miRNA-mRNA pairs without taking into account target complementarity (65-68). Among the results obtained by these methods, the miR-29 family was identified to recurrently regulate the DNA demethylation pathway in (60) and a signature of four miRNAs (miR-320d, miR-139-5p, miR-567 and let-7c) was proposed for breast cancer grade classification in (61). 
All these approaches, powerful for precise miRNA targets identification, have limited application in the context of miRNA biomarkers detection. In fact, given that they deal with miRNA-mRNA couples, their evaluation of the miRNA driving role is always conditioned by the activity of the associated mRNA. To overcome this limitation, methodologies that are centered on microRNAs, corresponding to group (ii), are needed. The most common and well-defined miRNA-centered procedure taking advantage of both miRNA and mRNA expression data involves a first step of microRNA differential expression analysis, in which active microRNAs are detected, followed by the evaluation of their regulatory effect on mRNAs, in which the intersection between the miRNA predicted targets and the group of regulated genes emerging from the expression data is computed. The set of mRNAs regulated by each microRNA is generally evaluated studying the anti-correlation between the expression values of the miRNA and those of its targets. A popular example of this kind of approach is MAGIA (69), but a similar procedure is also applied in other works (70-75). Interestingly, such approach led to the identification in (73) of two miRNA signatures (miR-16, miR-155, miR-125b, miR-374a and miR-16, miR-125b, miR-374a, miR- miR-374b, miR-421, miR-655, miR-497) predictive of triple negative breast cancer overall survival and distant-disease free survival, respectively. Alternative measures employed to capture the miRNA-target activity from expression data are: inverse expression (MMIA (76)), which is less stringent than correlation, penalized Cox regression (77) and Independent Component Analysis (ICA), which was proved to give more reliable results than correlation (78). In the last case eight microRNAs involved in type 1 diabetes regulation were identified, three of which (miR-124, miR-375 and miR-204) were already documented to have an important role in this disease.

Given that these approaches evaluate the miRNA activity based not only on its expression but also on its regulatory effects, they tend to be more accurate than those described in the previous sections. However they do not capture all those cases in which a miRNA up-regulates its target mRNAs, phenomenon that has been abundantly observed (79-82). To take into account also this regulatory mechanism, bioinformatics strategies that do not use miRNA-mRNA sequence complementarity have been developed. Some of them apply the procedure described above without using target prediction, i.e. miRNA differential expression followed by correlation analysis with all the expressed mRNAs $(83,84)$. In this case both positive and negative correlations are considered. Such basic strategy proved is effectiveness by identifying miR-648 as a novel candidate miRNA biomarker in prostate cancer (84). Some modifications of this pipeline have then been also proposed. Hua et al. (85) substitute correlation with summed Pearson Correlation Coefficient (sPCC) that is less affected by signal distortions than correlation. Engstrom et al. (86) and Genovese et al. (87) replace correlation with Mutual Information (MI), which does not assume a linear relationship between miRNA and mRNA expression values. Other methods substitute miRNA differential expression analysis with alternative approaches (87-89). Genovese et al. (87) and Zadran et al. (88) employ information-theoretic approaches, Context Likelihood of Relatedness modeling algorithm and Surprisal analysis, respectively. Finally, Sehgal and coauthors (89) substitute miRNA differential expression analysis with a selection based on the prognostic significance, more advisable for clinical application. The use of measures alternative to correlation led in (87) to the identification of a novel regulation of TGF- $\beta$ signaling via Smad4 by miR-34a.

The advantage of the above methods in respect to those that intersect predicted targets with expression correlation is that they are more general and thus they can capture more complex miRNA-mRNA regulatory events. However, given that they are less specific, they tend to be considerably prone to false positive predictions. In this regard, a good compromise is represented by the combined use of miRNA targets prediction and miRNA/mRNA expression analysis without computing the intersection of the two. Examples of these approaches are represented by Context-Specific MicroRNA analysis (CosMic) (90), TargetRunningSum (91) and MicroRNA Master Regulator Analysis (MMRA) (92, 93). The first two pipelines use a strategy closely related to gene set enrichment analysis (GSEA) to calculate the enrichment of the top ranked sequence-based predicted targets by the top ranked correlated genes. MMRA performs a more complex procedure involving four sequential steps, each aimed at progressively reducing the number of candidate microRNAs: (i) differential expression analysis to highlight microRNAs with subtype-specific expression; (ii) target transcript enrichment analysis, to further select those microRNAs whose predicted targets are enriched in the associated subtype mRNA signature; (iii) network analysis, in which an mRNA network is constructed around each microRNA using ARACNE and tested for enrichment in signature genes; (iv) identification of microRNAs whose expression 'explains' the expression of subtype signature genes, using stepwise linear regression (SLR) analysis. The pipelines described so far have been typically applied to distinguish tumour from normal tissue or to test the involvement of microRNAs in a pathway based on expression profiles derived from cell lines under stimulation. On the contrary, MMRA and TargetRunningSum are the first designed for miRNA biomarker identification in tumor subtypes, a comparison characterized by much lower variations. Moreover, as done only for CoMeTa so far, the results of both CosMic and MMRA were experimentally validated in cancer cell lines by microRNA silencing experiments. In particular, the control of migration by miR-20a, miR-212 and miR-671-5p, identified by CosMic, was validated in MCF10A cells after EGF stimulation. On the other hand, miR-429, miR200b, miR-203 and miR-194, predicted by MMRA to drive the stem-like aggressive and poor prognosis colorectal cancer (CRC) subtype, were functionally validated in HT29, NCIH508 and SW403 CRC cell lines, suggesting the use of these miRNAs as biomarker and/or therapeutic molecules in the aggressive CRC subtype. Therefore MMRA is the only pipeline in its category able to identify candidate miRNA driver of cancer subtypes whose role has been functionally verified.

Overall, the approaches based on the combined use or miRNA and mRNA expression described in this section allow not only to strengthen miRNA prediction as a biomarker but also to reconstruct the effects of the miRNA deregulation on the 
cellular functions. They can thus lead to the identification of central pathways deregulated in cancer, having direct consequences in the development of new therapeutic strategies. Moreover, the outputs of such approaches can help identifying key regulatory mechanisms involved in drug resistance that can be targeted in the context of drugs combination.

\subsection{Methods taking into account the miRNA-TF crosstalk}

The translation of an mRNA into protein is a multi-step process regulated at the transcriptional and post-transcriptional level by Transcription Factors (TFs) and microRNAs, respectively. Considering that TFs and miRNAs play a prominent role in transcription, their own and target sequences represent one of the major location of cancer-driver alterations. At the same time, given that they share a common regulatory logic, it is straightforward to hypothesize that they are able to cooperate. Therefore cancer onset or subtyping is more frequently characterized by a dysregulation in the synergistic miRNA-TF crosstalk rather than by the alteration of a single factor. As a consequence, to robustly identify miRNA biomarkers, it is important to consider the coordinated miRNA-TF activity, which is generally modeled using networks. MiRNAs, mRNAs, and TFs are the three classes of nodes in these networks, while edges are usually drawn integrating co-regulations inferred from miRNA/mRNA expression data with database derived interactions (e.g. TF-gene interaction form JASPAR, TRANSFAC and ECRbase; miRNA-gene interactions from PITA, miRANDA, TargetScan 5.0., RNAhybrid and Pictar, Microcosm, microrna.org, DIANA-microT, miRDB, RNA22 ; TF-miRNA interactions form mirGen2.0. and TransmiR). Moreover, a sign is associated to each graph edge corresponding to activation/inhibition depending if this connects a molecule that influences positively/negatively the level of another one. In this context, the different algorithms differ for the technique used to combine the database-derived and datadriven interactions. MAGIA ${ }^{2}$ (94), extension of the MAGIA algorithm described in the previous section, and mirConnX (95) reconstruct two independent networks. One derived from matched microRNA/mRNA expression data according to Person, Spearman correlation and mutual information. The other consistently retrieved from multiple interaction databases. The two networks are then integrated computing the intersection for MAGIA ${ }^{2}$ and through a weighted sum function for mirConnX. Interestingly, mirConnX proved to be performing particularly well in the detection of cancer associated miRNA-TF interactions. For example, it identified a feed-forward loop among SMAD TFs, let-7 d and HMGA2 gene, which is central in the regulation of epithelial to mesenchymal transition (EMT). These approaches can be employed only if a matched microRNA/mRNA expression dataset is available. Alternative methods, applicable also to unmatched miRNA/mRNA expression data, perform miRNA and mRNA differential expression analysis and then reconstruct the network whose nodes are represented by the differential molecules and whose links are derived from databases. MAGIA ${ }^{2}$ (supporting both procedures) and the pipelines by Ying et al. (96) and Samantarrai et al. (97) follow this idea. Interestingly, the work by Ying and coauthors put light on the role of miR-16 in triggering an accumulation of cells in G0/G1 through the silencing of multiple cell cycle genes and thus they suggested this miRNA as candidate biomarker for ovarian cancer. The integration of database and data-driven derived information has been finally performed also in other two completely new ways $(98,99)$. Gene4x $(98)$ combines mRNA expression data with database knowledge (including protein-protein interactions) through the use of multi-networks. The approach proposed by Yu and coauthors (99) uses a linear regression model taking into account both miRNA/mRNA expression and predicted regulatory relationships. Of note is the fact that multiple candidate biomarker microRNAs have been suggested for colorectal, pancreatic, lung and gastric cancer in (98). For example, MiR-337 was suggested as biomarker for survival in pancreatic cancer and indeed its overexpression had already been shown to induce the suppression of cell proliferation and invasion in pancreatic cancer. MiR153 was identified as prognostic marker in the same cancer and indeed it was already known to inhibit PDAC cell migration and invasion by targeting SNAI1.

The regulatory networks, obtained with the procedures described above, are usually composed of over-represented subnetwork patterns known as network motifs $(100,101)$. Among the various motifs mixed feed-forward loops (FFLs) are those playing a pivotal role in gene regulation and known to have an important role in cancer development (102). A typical mixed FFL consist of a TF that regulates the transcription of the miRNA and both the TF and the miRNA regulate a common set of target gene (103-106). Given that the study of mixed FFLs has emerged as a powerful tool to understand specific biological events, multiple research groups have investigated their involvement in cancer. Sun et al. (107) have first reconstructed the regulatory network of genes, TFs and microRNAs known to be involved in Glioblastoma (GBM) and then they have extracted significantly over-represented mixed motifs. With such approach, Sun et al. suggested six key miRNAs (miR-124, miR-137, miR-219-5p, miR-34a, miR-9, and miR-92b) involved in the Notch signaling pathway in GBM. Among them the most noteworthy one is miR34a, which regulates proteins involved in cell cycle, apoptosis, differentiation and cellular development. Afshar et al. (108) developed integraMiR a new tool for regulatory network reconstruction and detection of overrepresented FFLs. On the other hand, there are methods that do not reconstruct the network, but only explore all possible FFL combinations. Some of them reconstruct the FFLs using only databases information $(109,110)$. In $(110)$ the authors provide a comprehensive database of all possible FFLs involving MYC, a TF of crucial importance in several biological processes, using only experimentally validated interactions. In particular, the authors centered their discussion on three main FFL circuits: (i) MYC-PTEN-(miR-106b, miR-93, miR-25, miR-19a, miR-22, miR-26a, miR-193b, miR-23b) suggested to act as a noise buffering circuit that guarantees a steady level of PTEN, a tumour suppressor gene which plays an important role in various cancer related pathways; (ii) MYC-RB1-(miR106a, miR-106b, miR-17) which controls the expression of the retinoblastoma protein (RB1), a tumour suppressor shown to be dysfunctional in many types of cancer and (iii) MYC-VEGF-(miR-106b, miR-106a, miR-93, miR-34a, miR-20a, miR-17, miR16, miR-15a) involved in cell migration and apoptosis. Jiang at al. (111) and Yan et al. (112) studied the FFLs active in multiple cancer types. In (111) network motifs were reconstructed in 13 tumor types using predicted interactions. 26 of those motifs were 
then prioritized having a significant biological activity in at least 5 tumor types, where the biological activity was investigated through node differential expression and edge differential co-expression between tumor and normal tissue. In (112), instead six tumor types were examined for FFLs presence through the tool dChip-GemiNI developed by the authors in the same paper. DChip-GemiNI reconstructs the FFLs using different predictive databases and then selects significant FFL motifs through integration of network motifs and expression data. The significance of a motif is determined through the use of a network motif score (NMS) and false discovery rate (FDR). The NMS is a function of multiple scores, including TF and miRNA binding scores to their target sequences, differential expression P-values of the FFL components between normal and cancer tissues, and TF and miRNA's target enrichment in differentially expressed genes and miRNAs. The major limit in the use of the methods described above for miRNA biomarkers identification is that they describe interactions that are more complex than those of the other approaches. Indeed given that they try to capture regulatory processes jointly controlled by a miRNA and a TF their activity cannot be controlled by only looking at the behavior of the miRNA.

The employment of the approaches proposed in this section for biomarkers identification is limited by the fact that they take into account mechanisms that are too complex to be used in the clinics for cancer detection. However, their power is due to the fact that they can substantially help cancer management by predicting key driver mechanisms with possible therapeutic application.

\subsection{More recent integrative works considering also other data types}

The studies described so far are based on the use of expression data alone, they thus ignore all those effects that arise from the interaction among different genomics levels. However, cancer is a complex disease characterized by multiple levels of dysregulation, for this reason the generation of integrative approaches can be employed to better elucidate the role of small noncoding RNAs in cancer. With the current availability of large collections of multi-omics data, it is now possible to compare cancer and normal profiles in multi-omics dimension. The integrative studies designed for microRNA biomarker identification realized so far combine methylation with miRNA/mRNA expression data. Volinia S. and Croce C.M. (113) employed methylation and miRNA/mRNA expression data from TCGA to construct an integrated prognostic signature, composed of 7 miRNA (such as hsa-miR-328, hsa-miR-484, and hsa-miR-874) and 30 mRNA genes, for invasive breast cancer. RNAs were selected if being significant in the survival analysis in at least two prognosis related subgroups and if their DNA methylation profile was significantly associated with patients overall survival. Finally the identified signature was tested in eight independent datasets proving to perform better than previous ones for risk stratification. Rajamani D. and Bhasin M.K. (114) employed a network-based approach to integrate the same omics profiles (mRNA, miRNA, DNA methylation) in pancreatic ductal adenocarcinoma (PDAC). In particular, first multidimensional disease signatures were obtained using rank-based meta-analysis, then these signatures were integrated in a network constructed using knowledge-based interaction information. Finally key regulators were identified from the network based on centrality measures. Yang et al (115) investigated the role of microRNAs in the regulation of the ovarian cancer (OvCa) mesenchymal subtype through a multivariate linear regression model searching for differentially expressed genes whose expression was correlated with copy number alteration, DNA methylation, or associated miRNA expression. With such approach, eight miRNAs were predicted to be crucial in the regulation of the OvCa mesenchymal subtype. Follow-up functional experiments validated the role of miR-506 in inhibiting cell migration and in preventing TGF $\beta$ induced epithelial-mesenchymal transition by targeting SNAI2, a transcriptional repressor of E-cadherin.

Integration of multi-omics data is becoming nowadays a widely employed approach to decipher the complexity of diseases such as cancer. Using miRNA data along with other data types can define comprehensive prognosis for patient that would not be achieve with single data sets. It is foreseeable that muli-omic based prognosis as the potential to be the most accurate methodology to precisely risk stratify patient and will play an important role in therapeutic strategy choices. On the other side, one difficulty in determining the microRNAs activity is represented by the wide set of potential target genes. To more accurately determine miRNA targets, Photoactivatable-Ribonucleoside-Enhanced Crosslinking and Immunoprecipitation (PARCLIP)-based methodologies (116), able to experimentally identify microRNA-target interactions in a genome-wide manner, have been designed in the last years. However the current collection of miRNA targets identified through the PAR-CLIP technology is restricted to a subset of the expressed microRNAs. For this reason the data obtained with this experimental technique have been recently combined with predictive approaches to increase the accuracy of the reconstructed miRNA-target interactions. Farazi and coauthors (117) identified miRNAs controlling subtype-specific pathways in breast cancer by training a regression model to rank and select miRNA-target interactions from TargetScan predictions that display similar characteristics to AGO2-PAR-CLIP targets and then prioritized miRNA regulatory activity based on association with expression of respective validated targets. The results of this approach suggest that miR-17, miR-19a, miR-25, and miR-200b show high regulatory activity in the triplenegative, basal-like subtype, whereas miR-22 and miR-24 do so in the HER2 subtype. Hamilton et al. (10) identified a pancancer, coregulated oncogenic microRNA 'superfamily' by integrating the atlas of AGO-PAR-CLIP-based microRNA targets with microRNA/mRNA expression, copy number variation (CNV) and exome-sequencing datasets.

\subsection{Methods considering the miRNA-miRNA synergistic effect}

These few decades of research on miRNA regulation have evidenced that in cancer, as in other contexts, miRNAs frequently act in a combined manner (118). The availability of large datasets derived from high-throughput experiments has allowed researchers to start investigating the synergistic relationships among miRNAs. Some computational methods have then 
been designed to predict genes and pathway jointly regulated by a set of microRNAs. The network-based methods that we have described above for the prioritization of differentially expressed microRNAs $(41,44-46)$ represent a first example of such kind of methodologies. Given that from the structure of the miRNA-miRNA network, used to prioritize miRNAs, it is also possible to elucidate their combined effect. Some methods have then been specifically designed for the identification of synergic microRNAs regulatory modules (119-121). Zhang et al (119) designed mirSRN (miRNA synergistic regulatory network), to infer miRNA synergism in human molecular systems by considering both downstream miRNA targets and upstream TF regulation. Xu et al. (121) constructed a miRNA-miRNA functional synergistic network via co-regulating miRNA modules satisfying three conditions: common targets, enriched in the same gene ontology category and close proximity in the protein interaction network. The same authors compared the miRNA synergistic network obtained on normal and tumor tissue observing an increased frequency of synergism in the disease network. Two well-known examples of cooperating microRNA sets are represented by miRNA families and genomically clustered microRNAs (122). MiRNA families are composed of miRNAs that share the same seed region and thus can be captured by all those approaches that evaluate synergism by looking at the number of common targets between groups of microRNAs. On the other hand, what is striking about miRNA clusters is that they frequently contain representatives from different miRNA families, meaning that the miRNAs of a given cluster can target different mRNAs, but surprisingly they have been shown to jointly regulate proteins in close proximity of the PPI network (123), or belonging to the same pathway (124). The role of some well-known miRNA clusters in cancer has been largely studied experimentally (118). However more than half of the total human microRNAs are organized into genomic clusters. If this is not a random event, we can thus hypothesize an involvement of other clustered miRNAs in cancer. The systematic investigation of the role of miRNA genomic clusters in cancer can be only realized computationally. By now, only two computational works exist about miRNA clusters $(125,126)$. They are both based on miRNA differential expression analysis, but no methodologies have yet been designed for the identification of biomarker miRNA clusters employing more sophisticated steps as those described above for single miRNA pipelines.

\section{CONCLUSIONS AND PERSPECTIVES}

Since 2002, when the involvement of $m i R-15 / 16$ in CLL was described, bioinformatic approaches contributed greatly in elucidating the role of miRNAs in cancer. One of the causes of the high interest in miRNAs activity in cancer is given by the fact that these tiny molecules are attractive candidates for employment as biomarkers. In fact, miRNAs are known to be very stable in formalined tissues, which are the common source of samples for biomarker analysis, and they are present in body fluids, which makes their analysis possible by less invasive methods and hence more practical in clinical settings. However, the full potential of miRNAs should not be exhausted in their use as biomarkers. Future research should increment the development and delivery of miRNA-based drugs. In this respect, some miRNAs have already shown promising results (127). Moreover, to increase the efficacy of currently used non-miRNA treatments, miRNAs can be employed to overcome resistance by acting on the multiple genes associated with a chemoresistant phenotype. Outstanding challenges remain to be overcome in order to achieve this goal. The two main problems in miRNA-based therapies are their poor cellular uptake due to their size and negative charge, as well as the off target effects due to the fact that a miRNA affects hundreds of transcripts in different tissues. To overcome these limitations nanoparticles and polymers as well as virus-based approaches are starting to be employed and overall, targeting miRNAs to reprogram regulatory mechanisms in cancer remains a strategy with strong potential and chances for success.

The achievement of such a goal in a less timing and resource demanding way can be performed thanks to the support of systems biology. In fact, elucidating the involvement of microRNAs in cancer onset and subtyping can help in the prioritization of the key miRNAs having a promising power in theranostics. In this review the state-of-art computational approaches for the detection of driver microRNAs in cancer have been comprehensively described. Concerning the existing methods, those combining miRNA expression with other measurements (e.g. mRNA expression, methylation) are those giving better performances. In particular, the approaches combining miRNA and mRNA expression gave the best performances leading to output miRNAs whose key role was also validated in functional experiments. The overall results seem thus to indicate that integration of different data types is the key to improve the future development of miRNA-based theranostic tools.

The majority of the approaches here proposed are devoted to elucidate the involvement of single microRNAs in cancer. However, miRNAs have been shown to frequently act in a combined manner, both in cancer and in other contexts. In particular, a well-known example of cooperating microRNA sets is represented by genomically clustered microRNAs. What is striking about miRNA clusters is that their components can target different mRNAs that surprisingly jointly regulate proteins in close proximity of the PPI network (118), or belonging to the same pathway (119). The systematic investigation of the role of miRNA genomic clusters in cancer can be only realized computationally and by now no sophisticated methodologies have been designed for the identification of biomarker miRNA clusters. For this reason, the design of methodologies centered on genomically clustered microRNAs should probably represent the next step to achieve in computational biology in order to improve the actual identification of miRNAs in theranostics.

\section{ACKNOWLEDGMENTS}

The publication of this article has received funding from the ITMO Cancer Sysbio Program (Mathematical Modeling 
of Molecular Mechanisms involved in Medulloblastoma progression - M5 project).

\section{REFERENCES}

1. G. A. Calin, C.-G. Liu, C. Sevignani, M. Ferracin, N. Felli, C. D. Dumitru, M. Shimizu, A. Cimmino, S. Zupo, M. Dono, M. L. Dell'Aquila, H. Alder, L. Rassenti, T. J. Kipps, F. Bullrich, M. Negrini and C. M. Croce: MicroRNA profiling reveals distinct signatures in B cell chronic lymphocytic leukemias. Proceedings of the National Academy of Sciences of the United States of America, 101(32), 11755-11760 (2004) doi:10.1.073/pnas.0404432101

2. R. C. Lee, R. L. Feinbaum and V. Ambros: The C. elegans heterochronic gene lin-4 encodes small RNAs with antisense complementarity to lin-14. Cell, 75(5), 843-854 (1993)

3. B. Wightman, I. Ha and G. Ruvkun: Posttranscriptional regulation of the heterochronic gene lin-14 by lin-4 mediates temporal pattern formation in C. elegans. Cell, 75(5), 855-862 (1993)

4. N. Morozova, A. Zinovyev, N. Nonne, L. L. Pritchard, A. N. Gorban and A. Harel-Bellan: Kinetic signatures of microRNA modes of action. RNA, 18(9), 1635-1655 (2012) doi:10.1.261/rna.032284.1.12

5. V. N. Kim: MicroRNA biogenesis: coordinated cropping and dicing. Nature Reviews. Molecular Cell Biology, 6(5), 376-385 (2005) doi:10.1.038/nrm1644

6. P. Brodersen and O. Voinnet: Revisiting the principles of microRNA target recognition and mode of action. Nature Reviews. Molecular Cell Biology, 10(2), 141-148 (2009) doi:10.1.038/nrm2619

7. G. A. Calin, C. Sevignani, C. D. Dumitru, T. Hyslop, E. Noch, S. Yendamuri, M. Shimizu, S. Rattan, F. Bullrich, M. Negrini and C. M. Croce: Human microRNA genes are frequently located at fragile sites and genomic regions involved in cancers. Proceedings of the National Academy of Sciences of the United States of America, 101(9), 2999-3004 (2004) doi:10.1.073/pnas.0307323101

8. S. Volinia, G. A. Calin, C. G. Liu, S. Ambs, A. Cimmino, F. Petrocca, R. Visone, M. Iorio, C. Roldo, M. Ferracin, R. L. Prueitt, N. Yanaihara, G. Lanza, A. Scarpa, A. Vecchione, M. Negrini, C. C. Harris and C. M. Croce: A microRNA expression signature of human solid tumors defines cancer gene targets. Proceedings of the National Academy of Sciences, 103(7), 2257-2261 (2006) doi:10.1.073/pnas.0510565103

9. M. Garofalo, G. Di Leva, G. Romano, G. Nuovo, S.-S. Suh, A. Ngankeu, C. Taccioli, F. Pichiorri, H. Alder, P. Secchiero, P. Gasparini, A. Gonelli, S. Costinean, M. Acunzo, G. Condorelli and C. M. Croce: miR-221\&222 regulate TRAIL resistance and enhance tumorigenicity through PTEN and TIMP3 downregulation. Cancer Cell, 16(6), 498-509 (2009) doi:10.1.016/j.ccr.2009.1.0.0.14

10. M. P. Hamilton, K. Rajapakshe, S. M. Hartig, B. Reva, M. D. McLellan, C. Kandoth, L. Ding, T. I. Zack, P. H. Gunaratne, D. A. Wheeler, C. Coarfa and S. E. McGuire: Identification of a pan-cancer oncogenic microRNA superfamily anchored by a central core seed motif. Nature Communications, 4 (2013) doi:10.1.038/ncomms3730

11. Q. Huang, K. Gumireddy, M. Schrier, C. le Sage, R. Nagel, S. Nair, D. A. Egan, A. Li, G. Huang, A. J. Klein-Szanto, P. A. Gimotty, D. Katsaros, G. Coukos, L. Zhang, E. Puré and R. Agami: The microRNAs miR-373 and miR-520c promote tumour invasion and metastasis. Nature Cell Biology, 10(2), 202-210 (2008) doi:10.1.038/ncb1681

12. L. Ma, J. Teruya-Feldstein and R. A. Weinberg: Tumour invasion and metastasis initiated by microRNA-10b in breast cancer. Nature, 449(7163), 682-688 (2007) doi:10.1.038/nature06174

13. L. F. Sempere, M. Christensen, A. Silahtaroglu, M. Bak, C. V. Heath, G. Schwartz, W. Wells, S. Kauppinen and C. N. Cole: Altered MicroRNA expression confined to specific epithelial cell subpopulations in breast cancer. Cancer Research, 67(24), 11612-11620 (2007) doi:10.1.158/0008-5472.CAN-07-5019

14. C. Blenkiron, L. D. Goldstein, N. P. Thorne, I. Spiteri, S.-F. Chin, M. J. Dunning, N. L. Barbosa-Morais, A. E. Teschendorff, A. R. Green, I. O. Ellis, S. Tavaré, C. Caldas and E. A. Miska: MicroRNA expression profiling of human breast cancer identifies new markers of tumor subtype. Genome Biology, 8(10), R214 (2007) doi:10.1.186/gb-2007-8-10-r214

15. M. Hanke, K. Hoefig, H. Merz, A. C. Feller, I. Kausch, D. Jocham, J. M. Warnecke and G. Sczakiel: A robust methodology to study urine microRNA as tumor marker: microRNA-126 and microRNA-182 are related to urinary bladder cancer. Urologic Oncology, 28(6), 655-661 (2010) doi:10.1.016/j.urolonc.2009.0.1.0.27 
16. C. H. Lawrie, S. Gal, H. M. Dunlop, B. Pushkaran, A. P. Liggins, K. Pulford, A. H. Banham, F. Pezzella, J. Boultwood, J. S. Wainscoat, C. S. R. Hatton and A. L. Harris: Detection of elevated levels of tumour-associated microRNAs in serum of patients with diffuse large B-cell lymphoma. British Journal of Haematology, 141(5), 672-675 (2008) doi:10.1.111/j.13652141.2.008.0.7077.x

17. M. V. Iorio and C. M. Croce: MicroRNA dysregulation in cancer: diagnostics, monitoring and therapeutics. A comprehensive review(1757-4684 (Electronic)) doi:D - NLM: PMC3376845 EDAT- 2012/02/22 06:00 MHDA- 2012/07/17 06:00 CRDT2012/02/22 06:00 PHST- 2011/10/31 (received) PHST- 2011/12/12 (revised) PHST- 2011/12/21 (accepted) AID 10.1.002/emmm.201100209 (doi) PST - ppublish

18. C. P. Gomes, L. Cho Jh Fau - Hood, O. L. Hood L Fau - Franco, R. W. Franco Ol Fau - Pereira, K. Pereira Rw Fau - Wang and K. Wang: A Review of Computational Tools in microRNA Discovery(1664-8021 (Linking)) doi:D - NLM: PMC3654206 OTO - NOTNLM

19. J. K. Banwait and D. R. Bastola: Contribution of bioinformatics prediction in microRNA-based cancer therapeutics(18728294 (Electronic)) doi:D - NLM: NIHMS642707

\section{D - NLM: PMC4277182 OTO - NOTNLM}

20. L. C. Emmanuel Barillot, Philippe Hupe, Jean-Philippe Vert, Andrei Zinovyev: Computational Systems Biology of Cancer. CRC Press (2012)

21. J. M. Thomson, J. Parker, C. M. Perou and S. M. Hammond: A custom microarray platform for analysis of microRNA gene expression. Nature Methods, 1(1), 47-53 (2004) doi:10.1.038/nmeth704

22. C.-G. Liu, G. A. Calin, B. Meloon, N. Gamliel, C. Sevignani, M. Ferracin, C. D. Dumitru, M. Shimizu, S. Zupo, M. Dono, H. Alder, F. Bullrich, M. Negrini and C. M. Croce: An oligonucleotide microchip for genome-wide microRNA profiling in human and mouse tissues. Proceedings of the National Academy of Sciences of the United States of America, 101(26), 9740-9744 (2004) doi:10.1.073/pnas.0403293101

23. Y. Sun, S. Koo, N. White, E. Peralta, C. Esau, N. M. Dean and R. J. Perera: Development of a micro-array to detect human and mouse microRNAs and characterization of expression in human organs. Nucleic Acids Research, 32(22), e188 (2004) doi:10.1.093/nar/gnh186

24. P. T. Nelson, D. A. Baldwin, L. M. Scearce, J. C. Oberholtzer, J. W. Tobias and Z. Mourelatos: Microarray-based, highthroughput gene expression profiling of microRNAs. Nature Methods, 1(2), 155-161 (2004) doi:10.1.038/nmeth717

25. O. Barad, E. Meiri, A. Avniel, R. Aharonov, A. Barzilai, I. Bentwich, U. Einav, S. Gilad, P. Hurban, Y. Karov, E. K. Lobenhofer, E. Sharon, Y. M. Shiboleth, M. Shtutman, Z. Bentwich and P. Einat: MicroRNA expression detected by oligonucleotide microarrays: system establishment and expression profiling in human tissues. Genome Research, 14(12), 24862494 (2004) doi:10.1.101/gr.2845604

26. J. Lu, G. Getz, E. A. Miska, E. Alvarez-Saavedra, J. Lamb, D. Peck, A. Sweet-Cordero, B. L. Ebert, R. H. Mak, A. A. Ferrando, J. R. Downing, T. Jacks, H. R. Horvitz and T. R. Golub: MicroRNA expression profiles classify human cancers. Nature, 435(7043), 834-838 (2005) doi:10.1.038/nature03702

27. T. Babak, W. Zhang, Q. Morris, B. J. Blencowe and T. R. Hughes: Probing microRNAs with microarrays: tissue specificity and functional inference. RNA (New York, N.Y.), 10(11), 1813-1819 (2004) doi:10.1.261/rna.7119904

28. M. Riaz, M. T. M. van Jaarsveld, A. Hollestelle, W. J. C. Prager-van der Smissen, A. A. J. Heine, A. W. M. Boersma, J. Liu, J. Helmijr, B. Ozturk, M. Smid, E. A. Wiemer, J. A. Foekens and J. W. M. Martens: miRNA expression profiling of 51 human breast cancer cell lines reveals subtype and driver mutation-specific miRNAs. Breast Cancer Research, 15(2), R33 (2013) doi:10.1.186/bcr3415

29. S. Volinia, M. Galasso, M. E. Sana, T. F. Wise, J. Palatini, K. Huebner and C. M. Croce: Breast cancer signatures for invasiveness and prognosis defined by deep sequencing of microRNA. Proceedings of the National Academy of Sciences, 109(8), 3024-3029 (2012) doi:10.1.073/pnas.1200010109

30. D.-F. Liu, J.-T. Wu, J.-M. Wang, Q.-Z. Liu, Z.-L. Gao and Y.-X. Liu: MicroRNA expression profile analysis reveals diagnostic biomarker for human prostate cancer. Asian Pacific journal of cancer prevention: APJCP, 13(7), 3313-3317 (2012) 
31. S. Ali, H. Dubaybo, R. E. Brand and F. H. Sarkar: Differential Expression of MicroRNAs in Tissues and Plasma Co-exists as a Biomarker for Pancreatic Cancer. Journal of Cancer Science \& Therapy, 7(11), 336-346 (2015) doi:10.4.172/19485956.1.000372

32. J. Ma, Y. Lin, M. Zhan, D. L. Mann, S. A. Stass and F. Jiang: Differential miRNA expressions in peripheral blood mononuclear cells for diagnosis of lung cancer. Laboratory Investigation, 95(10), 1197-1206 (2015) doi:10.1.038/labinvest.2015.8.8

33. Y. Chen and R. L. Stallings: Differential Patterns of MicroRNA Expression in Neuroblastoma Are Correlated with Prognosis, Differentiation, and Apoptosis. Cancer Research, 67(3), 976-983 (2007) doi:10.1.158/0008-5472.CAN-06-3667

34. E. J. Lee, Y. Gusev, J. Jiang, G. J. Nuovo, M. R. Lerner, W. L. Frankel, D. L. Morgan, R. G. Postier, D. J. Brackett and T. D. Schmittgen: Expression profiling identifies microRNA signature in pancreatic cancer. International Journal of Cancer, 120(5), 1046-1054 (2006) doi:10.1.002/ijc.22394

35. M. V. Iorio, M. Ferracin, C. G. Liu, A. Veronese, R. Spizzo, S. Sabbioni, E. Magri, M. Pedriali, M. Fabbri, M. Campiglio, S. Menard, J. P. Palazzo, A. Rosenberg, P. Musiani, S. Volinia, I. Nenci, G. A. Calin, P. Querzoli, M. Negrini and C. M. Croce: MicroRNA Gene Expression Deregulation in Human Breast Cancer. Cancer Research, 65(16), 7065-7070 (2005) doi:10.1.158/0008-5472.CAN-05-1783

36. Y.-G. Tan, Y.-F. Zhang, C.-J. Guo, M. Yang and M.-Y. Chen: Screening of differentially expressed microRNA in ulcerative colitis related colorectal cancer. Asian Pacific Journal of Tropical Medicine, 6(12), 972-976 (2013) doi:10.1.016/S19957645(13)60174-1

37. J.-L. Wang, Y. Hu, X. Kong, Z.-H. Wang, H.-Y. Chen, J. Xu and J.-Y. Fang: Candidate microRNA Biomarkers in Human Gastric Cancer: A Systematic Review and Validation Study. PLoS ONE, 8(9), e73683 (2013) doi:10.1.371/journal.pone.0073683

38. X. Li, Q. Wang, Y. Zheng, S. Lv, S. Ning, J. Sun, T. Huang, Q. Zheng, H. Ren, J. Xu, X. Wang and Y. Li: Prioritizing human cancer microRNAs based on genes' functional consistency between microRNA and cancer. Nucleic Acids Research, 39(22), e153e153 (2011) doi:10.1.093/nar/gkr770

39. L. Zhang, S. Volinia, T. Bonome, G. A. Calin, J. Greshock, N. Yang, C. G. Liu, A. Giannakakis, P. Alexiou, K. Hasegawa, C. N. Johnstone, et al.: Genomic and epigenetic alterations deregulate microRNA expression in human epithelial ovarian cancer. Proceedings of the National Academy of Sciences, 105(19), 7004-7009 (2008) doi:10.1.073/pnas.0801615105

40. B. Seliger, S. Jasinski, S. P. Dressler, F. M. Marincola, C. V. Recktenwald, E. Wang and R. Lichtenfels: Linkage of microRNA and Proteome-Based Profiling Data Sets: A Perspective for the Priorization of Candidate Biomarkers in Renal Cell Carcinoma? Journal of Proteome Research, 10(1), 191-199 (2011) doi:10.1.021/pr1011137

41. A. Piepoli, F. Tavano, M. Copetti, T. Mazza, O. Palumbo, A. Panza, F. F. di Mola, V. Pazienza, G. Mazzoccoli, G. Biscaglia, A. Gentile, N. Mastrodonato, M. Carella, F. Pellegrini, P. di Sebastiano and A. Andriulli: Mirna Expression Profiles Identify Drivers in Colorectal and Pancreatic Cancers. PLoS ONE, 7(3), e33663 (2012) doi:10.1.371/journal.pone.0033663

42. X. Zhang, Y. Peng, Z. Jin, W. Huang, Y. Cheng, Y. Liu, X. Feng, M. Yang, Y. Huang, Z. Zhao, L. Wang, Y. Wei, X. Fan, D. Zheng and S. J. Meltzer: Integrated miRNA profiling and bioinformatics analyses reveal potential causative miRNAs in gastric adenocarcinoma. Oncotarget, 6(32), 32878-32889 (2015) doi:10.1.8632/oncotarget.5419

43. G. A. Pavlopoulos, M. Secrier, C. N. Moschopoulos, T. G. Soldatos, S. Kossida, J. Aerts, R. Schneider and P. G. Bagos: Using graph theory to analyze biological networks. BioData Mining, 4(1) (2011) doi:10.1.186/1756-0381-4-10

44. S. Volinia, M. Galasso, S. Costinean, L. Tagliavini, G. Gamberoni, A. Drusco, J. Marchesini, N. Mascellani, M. E. Sana, R. Abu Jarour, C. Desponts, et al.: Reprogramming of miRNA networks in cancer and leukemia. Genome Research, 20(5), 589-599 (2010) doi:10.1.101/gr.098046.1.09

45. X. Zeng, X. Zhang and Q. Zou: Integrative approaches for predicting microRNA function and prioritizing disease-related microRNA using biological interaction networks. Briefings in Bioinformatics, 17(2), 193-203 (2016) doi:10.1.093/bib/bbv033

46. J. Li, K. Lei, Z. Wu, W. Li, G. Liu, J. Liu, F. Cheng and Y. Tang: Network-based identification of microRNAs as potential pharmacogenomic biomarkers for anticancer drugs. Oncotarget (2014) doi:10.1.8632/oncotarget.10052 
47. C. P. Goswami and H. Nakshatri: PROGmiR: a tool for identifying prognostic miRNA biomarkers in multiple cancers using publicly available data. Journal of Clinical Bioinformatics, 2(1), 23 (2012) doi:10.1.186/2043-9113-2-23

48. D. Baek, J. Villén, C. Shin, F. D. Camargo, S. P. Gygi and D. P. BarTel: The impact of microRNAs on protein output. Nature, 455(7209), 64-71 (2008) doi:10.1.038/nature07242

49. M. Selbach, B. Schwanhäusser, N. Thierfelder, Z. Fang, R. Khanin and N. Rajewsky: Widespread changes in protein synthesis induced by microRNAs. Nature, 455(7209), 58-63 (2008) doi:10.1.038/nature07228

50. C. J. Creighton, A. K. Nagaraja, S. M. Hanash, M. M. Matzuk and P. H. Gunaratne: A bioinformatics tool for linking gene expression profiling results with public databases of microRNA target predictions. RNA (New York, N.Y.), 14(11), 2290-2296 (2008) doi:10.1.261/rna.1188208

51. X. Wu and M. Watson: CORNA: testing gene lists for regulation by microRNAs. Bioinformatics, 25(6), 832-833 (2009) doi:10.1.093/bioinformatics/btp059

52. Z. Liang, H. Zhou, Z. He, H. Zheng and J. Wu: mirAct: a web tool for evaluating microRNA activity based on gene expression data. Nucleic Acids Research, 39(suppl), W139-W144 (2011) doi:10.1.093/nar/gkr351

53. X.-M. Zhao, K.-Q. Liu, G. Zhu, F. He, B. Duval, J.-M. Richer, D.-S. Huang, C.-J. Jiang, J.-K. Hao and L. Chen: Identifying cancer-related microRNAs based on gene expression data. Bioinformatics (Oxford, England), 31(8), 1226-1234 (2015) doi:10.1.093/bioinformatics/btu811

54. V. A. Gennarino, G. D'Angelo, G. Dharmalingam, S. Fernandez, G. Russolillo, R. Sanges, M. Mutarelli, V. Belcastro, A. Ballabio, P. Verde, M. Sardiello and S. Banfi: Identification of microRNA-regulated gene networks by expression analysis of target genes. Genome Research, 22(6), 1163-1172 (2012) doi:10.1.101/gr.130435.1.11

55. T. Barrett, S. E. Wilhite, P. Ledoux, C. Evangelista, I. F. Kim, M. Tomashevsky, K. A. Marshall, K. H. Phillippy, P. M. Sherman, M. Holko, A. Yefanov, H. Lee, N. Zhang, C. L. Robertson, N. Serova, S. Davis and A. Soboleva: NCBI GEO: archive for functional genomics data sets--update. Nucleic Acids Research, 41(Database issue), D991-995 (2013) doi:10.1.093/nar/gks1193

56. T. J. Hudson, W. Anderson, A. Aretz, A. D. Barker, C. Bell, R. R. Bernabé, M. K. Bhan, F. Calvo, I. Eerola, D. S. Gerhard, A. Guttmacher, M. Guyer, F. M. Hemsley, et al.: International network of cancer genome projects. Nature, 464(7291), 993-998 (2010) doi:10.1.038/nature08987

57. Y.-P. Wang and K.-B. Li: Correlation of expression profiles between microRNAs and mRNA targets using NCI-60 data. BMC Genomics, 10(1), 218 (2009) doi:10.1.186/1471-2164-10-218

58. V. Jayaswal, M. Lutherborrow, D. D. F. Ma and Y. H. Yang: Identification of microRNA-mRNA modules using microarray data. BMC Genomics, 12(1), 138 (2011) doi:10.1.186/1471-2164-12-138

59. W. Zhang, A. Edwards, W. Fan, E. K. Flemington and K. Zhang: miRNA-mRNA Correlation-Network Modules in Human Prostate Cancer and the Differences between Primary and Metastatic Tumor Subtypes. PLoS ONE, 7(6), e40130 (2012) doi:10.1.371/journal.pone.0040130

60. A. Jacobsen, J. Silber, G. Harinath, J. T. Huse, N. Schultz and C. Sander: Analysis of microRNA-target interactions across diverse cancer types. Nature Structural \& Molecular Biology, 20(11), 1325-1332 (2013) doi:10.1.038/nsmb.2678

61. C. Cava, G. Bertoli, M. Ripamonti, G. Mauri, I. Zoppis, P. A. D. Rosa, M. C. Gilardi and I. Castiglioni: Integration of mRNA Expression Profile, Copy Number Alterations, and microRNA Expression Levels in Breast Cancer to Improve Grade Definition. PLOS ONE, 9(5), e97681 (2014) doi:10.1.371/journal.pone.0097681

62. N. Hecker, C. Stephan, H.-J. Mollenkopf, K. Jung, R. Preissner and H.-A. Meyer: A New Algorithm for Integrated Analysis of miRNA-mRNA Interactions Based on Individual Classification Reveals Insights into Bladder Cancer. PLoS ONE, 8(5), e64543 (2013) doi:10.1.371/journal.pone.0064543

63. J. Xu, C.-X. Li, J.-Y. Lv, Y.-S. Li, Y. Xiao, T.-T. Shao, X. Huo, X. Li, Y. Zou, Q.-L. Han, X. Li, L.-H. Wang and H. Ren: Prioritizing candidate disease miRNAs by topological features in the miRNA target-dysregulated network: case study of prostate cancer. Molecular Cancer Therapeutics, 10(10), 1857-1866 (2011) doi:10.1.158/1535-7163.MCT-11-0055 
64. J. C. Huang, T. Babak, T. W. Corson, G. Chua, S. Khan, B. L. Gallie, T. R. Hughes, B. J. Blencowe, B. J. Frey and Q. D. Morris: Using expression profiling data to identify human microRNA targets. Nature Methods, 4(12), 1045-1049 (2007) doi:10.1.038/nmeth1130

65. B. Liu, L. Liu, A. Tsykin, G. J. Goodall, J. E. Green, M. Zhu, C. H. Kim and J. Li: Identifying functional miRNA-mRNA regulatory modules with correspondence latent dirichlet allocation. Bioinformatics, 26(24), $3105-3111$ (2010) doi:10.1.093/bioinformatics/btq576

66. B. Liu, J. Li, A. Tsykin, L. Liu, A. B. Gaur and G. J. Goodall: Exploring complex miRNA-mRNA interactions with Bayesian networks by splitting-averaging strategy. BMC Bioinformatics, 10(1), 408 (2009) doi:10.1.186/1471-2105-10-408

67. B. Liu, J. Li and A. Tsykin: Discovery of functional miRNA-mRNA regulatory modules with computational methods. Journal of Biomedical Informatics, 42(4), 685-691 (2009) doi:10.1.016/j.jbi.2009.0.1.0.05

68. L. Martignetti, K. Laud-Duval, F. Tirode, G. Pierron, S. Reynaud, E. Barillot, O. Delattre and A. Zinovyev: Antagonism Pattern Detection between MicroRNA and Target Expression in Ewing's Sarcoma. PLoS ONE, 7(7), e41770 (2012) doi:10.1.371/journal.pone.0041770

69. G. Sales, A. Coppe, A. Bisognin, M. Biasiolo, S. Bortoluzzi and C. Romualdi: MAGIA, a web-based tool for miRNA and Genes Integrated Analysis. Nucleic Acids Research, 38(Web Server), W352-W359 (2010) doi:10.1.093/nar/gkq423

70. I. Ulitsky, L. C. Laurent and R. Shamir: Towards computational prediction of microRNA function and activity. Nucleic Acids Research, 38(15), e160-e160 (2010) doi:10.1.093/nar/gkq570

71. M. Lionetti, M. Biasiolo, L. Agnelli, K. Todoerti, L. Mosca, S. Fabris, G. Sales, G. L. Deliliers, S. Bicciato, L. Lombardi, S. Bortoluzzi and A. Neri: Identification of microRNA expression patterns and definition of a microRNA/mRNA regulatory network in distinct molecular groups of multiple myeloma. Blood, 114(25), e20-e26 (2009) doi:10.1.182/blood-2009-08-237495

72. L. Ma, Y. Huang, W. Zhu, S. Zhou, J. Zhou, F. Zeng, X. Liu, Y. Zhang and J. Yu: An Integrated Analysis of miRNA and mRNA Expressions in Non-Small Cell Lung Cancers. PLoS ONE, 6(10), e26502 (2011) doi:10.1.371/journal.pone.0026502

73. L. Cascione, P. Gasparini, F. Lovat, S. Carasi, A. Pulvirenti, A. Ferro, H. Alder, G. He, A. Vecchione, C. M. Croce, C. L. Shapiro and K. Huebner: Integrated MicroRNA and mRNA Signatures Associated with Survival in Triple Negative Breast Cancer. PLoS ONE, 8(2), e55910 (2013) doi:10.1.371/journal.pone.0055910

74. S. Pizzini, A. Bisognin, S. Mandruzzato, M. Biasiolo, A. Facciolli, L. Perilli, E. Rossi, G. Esposito, M. Rugge, P. Pilati, S. Mocellin, D. Nitti, S. Bortoluzzi and P. Zanovello: Impact of microRNAs on regulatory networks and pathways in human colorectal carcinogenesis and development of metastasis. BMC Genomics, 14(1), 589 (2013) doi:10.1.186/1471-2164-14-589

75. J. Fu, W. Tang, P. Du, G. Wang, W. Chen, J. Li, Y. Zhu, J. Gao and L. Cui: Identifying MicroRNA-mRNA regulatory network in colorectal cancer by a combination of expression profile and bioinformatics analysis. BMC Systems Biology, 6(1), 68 (2012) doi:10.1.186/1752-0509-6-68

76. S. Nam, M. Li, K. Choi, C. Balch, S. Kim and K. P. Nephew: MicroRNA and mRNA integrated analysis (MMIA): a web tool for examining biological functions of microRNA expression. Nucleic Acids Research, 37(Web Server issue), W356-362 (2009) doi:10.1.093/nar/gkp294

77. F. M. Buffa, C. Camps, L. Winchester, C. E. Snell, H. E. Gee, H. Sheldon, M. Taylor, A. L. Harris and J. Ragoussis: microRNA-Associated Progression Pathways and Potential Therapeutic Targets Identified by Integrated mRNA and microRNA Expression Profiling in Breast Cancer. Cancer Research, 71(17), 5635-5645 (2011) doi:10.1.158/0008-5472.CAN-11-0489

78. C. H. Bang-Berthelsen, L. Pedersen, T. Fløyel, P. H. Hagedorn, T. Gylvin and F. Pociot: Independent component and pathway-based analysis of miRNA-regulated gene expression in a model of type 1 diabetes. BMC Genomics, 12(1), 97 (2011) doi:10.1.186/1471-2164-12-97

79. S. Vasudevan, Y. Tong and J. A. Steitz: Switching from Repression to Activation: MicroRNAs Can Up-Regulate Translation. Science, 318(5858), 1931-1934 (2007) doi:10.1.126/science.1149460

80. J. Yu, D. G. Ryan, S. Getsios, M. Oliveira-Fernandes, A. Fatima and R. M. Lavker: MicroRNA-184 antagonizes microRNA205 to maintain SHIP2 levels in epithelia. Proceedings of the National Academy of Sciences, 105(49), 19300-19305 (2008) doi:10.1.073/pnas.0803992105 
81. X. Liu, A. Nelson, X. Wang, N. Kanaji, M. Kim, T. Sato, M. Nakanishi, Y. Li, J. Sun, J. Michalski, A. Patil, H. Basma and S. I. Rennard: MicroRNA-146a modulates human bronchial epithelial cell survival in response to the cytokine-induced apoptosis. Biochemical and Biophysical Research Communications, 380(1), 177-182 (2009) doi:10.1.016/j.bbrc.2009.0.1.0.66

82. C. A. Gebeshuber, K. Zatloukal and J. Martinez: miR-29a suppresses tristetraprolin, which is a regulator of epithelial polarity and metastasis. EMBO reports, 10(4), 400-405 (2009) doi:10.1.038/embor.2009.9.

83. E. Enerly, I. Steinfeld, K. Kleivi, S.-K. Leivonen, M. R. Aure, H. G. Russnes, J. A. Rønneberg, H. Johnsen, R. Navon, E. Rødland, R. Mäkelä, B. Naume, M. Perälä, O. Kallioniemi, V. N. Kristensen, Z. Yakhini and A.-L. Børresen-Dale: miRNAmRNA Integrated Analysis Reveals Roles for miRNAs in Primary Breast Tumors. PLoS ONE, 6(2), e16915 (2011) doi:10.1.371/journal.pone.0016915

84. W. Zhang, J. Zang, X. Jing, Z. Sun, W. Yan, D. Yang, B. Shen and F. Guo: Identification of candidate miRNA biomarkers from miRNA regulatory network with application to prostate cancer. Journal of Translational Medicine, 12(1), 66 (2014) doi:10.1.186/1479-5876-12-66

85. Y. Hua, S. Duan, A. E. Murmann, N. Larsen, J. Kjems, A. H. Lund and M. E. Peter: miRConnect: Identifying Effector Genes of miRNAs and miRNA Families in Cancer Cells. PLoS ONE, 6(10), e26521 (2011) doi:10.1.371/journal.pone.0026521

86. R. E. Engstrom, B. J. Mondino, B. J. Glasgow, H. Pitchekian-Halabi and S. A. Adamu: Immune response to Staphylococcus aureus endophthalmitis in a rabbit model. Investigative Ophthalmology \& Visual Science, 32(5), 1523-1533 (1991)

87. G. Genovese, A. Ergun, S. A. Shukla, B. Campos, J. Hanna, P. Ghosh, S. N. Quayle, K. Rai, S. Colla, H. Ying, C.-J. Wu, S. Sarkar, Y. Xiao, J. Zhang, H. Zhang, L. Kwong, K. Dunn, W. R. Wiedemeyer, C. Brennan, H. Zheng, D. L. Rimm, J. J. Collins and L. Chin: microRNA regulatory network inference identifies miR-34a as a novel regulator of TGF- $\beta$ signaling in glioblastoma. Cancer Discovery, 2(8), 736-749 (2012) doi:10.1.158/2159-8290.CD-12-0111

88. S. Zadran, F. Remacle and R. D. Levine: miRNA and mRNA cancer signatures determined by analysis of expression levels in large cohorts of patients. Proceedings of the National Academy of Sciences of the United States of America, 110(47), 1916019165 (2013) doi:10.1.073/pnas.1316991110

89. V. Sehgal, E. G. Seviour, T. J. Moss, G. B. Mills, R. Azencott and P. T. Ram: Robust Selection Algorithm (RSA) for MultiOmic Biomarker Discovery; Integration with Functional Network Analysis to Identify miRNA Regulated Pathways in Multiple Cancers. PLOS ONE, 10(10), e0140072 (2015) doi:10.1.371/journal.pone.0140072

90. N. Bossel Ben-Moshe, R. Avraham, M. Kedmi, A. Zeisel, A. Yitzhaky, Y. Yarden and E. Domany: Context-specific microRNA analysis: identification of functional microRNAs and their mRNA targets. Nucleic Acids Research, 40(21), 1061410627 (2012) doi:10.1.093/nar/gks841

91. L. Martignetti, B. Tesson, A. Almeida, A. Zinovyev, G. C. Tucker, T. Dubois and E. Barillot: Detection of miRNA regulatory effect on triple negative breast cancer transcriptome. BMC Genomics, 16(Suppl 6), S4 (2015) doi:10.1.186/1471-2164-16-S6-S4

92. L. Cantini, L. Cantini, C. Isella, C. Petti, G. Picco, S. Chiola, E. Ficarra, M. Caselle and E. Medico: MMRA MicroRNA Master Regulator Analysis. Protocol Exchange (2015) doi:10.1.038/protex.2015.1.22

93. L. Cantini, C. Isella, C. Petti, G. Picco, S. Chiola, E. Ficarra, M. Caselle and E. Medico: MicroRNA-mRNA interactions underlying colorectal cancer molecular subtypes. Nature Communications, 6, 8878 (2015) doi:10.1.038/ncomms9878

94. A. Bisognin, G. Sales, A. Coppe, S. Bortoluzzi and C. Romualdi: MAGIA²: from miRNA and genes expression data integrative analysis to microRNA-transcription factor mixed regulatory circuits (2012 update). Nucleic Acids Research, 40(Web Server issue), W13-21 (2012) doi:10.1.093/nar/gks460

95. G. T. Huang, C. Athanassiou and P. V. Benos: mirConnX: condition-specific mRNA-microRNA network integrator. Nucleic Acids Research, 39(suppl), W416-W423 (2011) doi:10.1.093/nar/gkr276

96. H. Ying, J. Lv, T. Ying, J. Li, Q. Yang and Y. Ma: MicroRNA and transcription factor mediated regulatory network for ovarian cancer: regulatory network of ovarian cancer. Tumour Biology: The Journal of the International Society for Oncodevelopmental Biology and Medicine, 34(5), 3219-3225 (2013) doi:10.1.007/s13277-013-0892-y 
97. D. Samantarrai, M. Sahu, J. Roy, B. B. Mohanty, G. Singh, C. Bhushan and B. Mallick: Unraveling novel TF-miRNA regulatory crosstalk in metastasis of Soft Tissue Sarcoma. Scientific Reports, 5, 9742 (2015) doi:10.1.038/srep09742

98. L. Cantini, E. Medico, S. Fortunato and M. Caselle: Detection of gene communities in multi-networks reveals cancer drivers. Scientific Reports, 5, 17386 (2015) doi:10.1.038/srep17386

99. H. Yu, K. Tu, Y.-J. Wang, J.-Z. Mao, L. Xie, Y.-Y. Li and Y.-X. Li: Combinatorial network of transcriptional regulation and microRNA regulation in human cancer. BMC Systems Biology, 6(1), 61 (2012) doi:10.1.186/1752-0509-6-61

100. U. Alon: An introduction to systems biology: design principles of biological circuits. Chapman \& Hall/CRC, Boca Raton, FL (2007)

101. U. Alon: Network motifs: theory and experimental approaches. Nature Reviews Genetics, 8(6), 450-461 (2007) doi:10.1.038/nrg2102

102. Q. Wu, H. Qin, Q. Zhao and X. X. He: Emerging role of transcription factor-microRNA-target gene feed-forward loops in cancer (Review). Biomedical Reports (2015) doi:10.3.892/br.2015.4.77

103. S. Mangan and U. Alon: Structure and function of the feed-forward loop network motif. Proceedings of the National Academy of Sciences, 100(21), 11980-11985 (2003) doi:10.1.073/pnas.2133841100

104. J. Tsang, J. Zhu and A. van Oudenaarden: MicroRNA-mediated feedback and feedforward loops are recurrent network motifs in mammals. Molecular Cell, 26(5), 753-767 (2007) doi:10.1.016/j.molcel.2007.0.5.0.18

105. A. Re, D. Corá, D. Taverna and M. Caselle: Genome-wide survey of microRNA-transcription factor feed-forward regulatory circuits in human. Molecular BioSystems, 5(8), 854 (2009) doi:10.1.039/b900177h

106. M. Osella, C. Bosia, D. Corá and M. Caselle: The Role of Incoherent MicroRNA-Mediated Feedforward Loops in Noise Buffering. PLoS Computational Biology, 7(3), e1001101 (2011) doi:10.1.371/journal.pcbi.1001101

107. J. Sun, X. Gong, B. Purow and Z. Zhao: Uncovering MicroRNA and Transcription Factor Mediated Regulatory Networks in Glioblastoma. PLoS Computational Biology, 8(7), e1002488 (2012) doi:10.1.371/journal.pcbi.1002488

108. A. S. Afshar, J. Xu and J. Goutsias: Integrative Identification of Deregulated MiRNA/TF-Mediated Gene Regulatory Loops and Networks in Prostate Cancer. PLoS ONE, 9(6), e100806 (2014) doi:10.1.371/journal.pone.0100806

109. C.-Y. Chen, S.-T. Chen, C.-S. Fuh, H.-F. Juan and H.-C. Huang: Coregulation of transcription factors and microRNAs in human transcriptional regulatory network. BMC bioinformatics, 12 Suppl 1, S41 (2011) doi:10.1.186/1471-2105-12-S1-S41

110. M. El Baroudi, D. Corà, C. Bosia, M. Osella and M. Caselle: A Curated Database of miRNA Mediated Feed-Forward Loops Involving MYC as Master Regulator. PLoS ONE, 6(3), e14742 (2011) doi:10.1.371/journal.pone.0014742

111. W. Jiang, R. Mitra, C.-C. Lin, Q. Wang, F. Cheng and Z. Zhao: Systematic dissection of dysregulated transcription factormiRNA feed-forward loops across tumor types. Briefings in Bioinformatics (2015) doi:10.1.093/bib/bbv107

112. Z. Yan, P. K. Shah, S. B. Amin, M. K. Samur, N. Huang, X. Wang, V. Misra, H. Ji, D. Gabuzda and C. Li: Integrative analysis of gene and miRNA expression profiles with transcription factor-miRNA feed-forward loops identifies regulators in human cancers. Nucleic Acids Research, 40(17), e135-e135 (2012) doi:10.1.093/nar/gks395

113. S. Volinia and C. M. Croce: Prognostic microRNA/mRNA signature from the integrated analysis of patients with invasive breast cancer. Proceedings of the National Academy of Sciences, 110(18), 7413-7417 (2013) doi:10.1.073/pnas.1304977110

114. D. Rajamani and M. K. Bhasin: Identification of key regulators of pancreatic cancer progression through multidimensional systems-level analysis. Genome Medicine, 8(1), 38 (2016) doi:10.1.186/s13073-016-0282-3

115. D. Yang, Y. Sun, L. Hu, H. Zheng, P. Ji, Chad V. Pecot, Y. Zhao, S. Reynolds, H. Cheng, R. Rupaimoole, D. Cogdell, M. Nykter, R. Broaddus, C. Rodriguez-Aguayo, G. Lopez-Berestein, J. Liu, I. Shmulevich, Anil K. Sood, K. Chen and W. Zhang: Integrated Analyses Identify a Master MicroRNA Regulatory Network for the Mesenchymal Subtype in Serous Ovarian Cancer. Cancer Cell, 23(2), 186-199 (2013) doi:10.1.016/j.ccr.2012.1.2.0.20 
116. M. Hafner, M. Landthaler, L. Burger, M. Khorshid, J. Hausser, P. Berninger, A. Rothballer, M. Ascano, A.-C. Jungkamp, M. Munschauer, A. Ulrich, G. S. Wardle, S. Dewell, M. Zavolan and T. Tuschl: Transcriptome-wide Identification of RNA-Binding Protein and MicroRNA Target Sites by PAR-CLIP. Cell, 141(1), 129-141 (2010) doi:10.1.016/j.cell.2010.0.3.0.09

117. T. A. Farazi, J. J. Ten Hoeve, M. Brown, A. Mihailovic, H. M. Horlings, M. J. van de Vijver, T. Tuschl and L. F. A. Wessels: Identification of distinct miRNA target regulation between breast cancer molecular subtypes using AGO2-PAR-CLIP and patient datasets. Genome Biology, 15(1), R9 (2014) doi:10.1.186/gb-2014-15-1-r9

118. C. Blenkiron and E. A. Miska: miRNAs in cancer: approaches, aetiology, diagnostics and therapy. Human Molecular Genetics, 16(R1), R106-R113 (2007) doi:10.1.093/hmg/ddm056

119. J. Zhang, T. Duy Le, L. Liu, J. He and J. Li: Identifying miRNA synergistic regulatory networks in heterogeneous human data via network motifs. Molecular bioSystems, 12(2), 454-463 (2016) doi:10.1.039/c5mb00562k

120. Z. Liu, J. Zhang, X. Yuan, B. Liu, Y. Liu, A. Li, Y. Zhang, X. Sun and S. Tuo: Detecting pan-cancer conserved microRNA modules from microRNA expression profiles across multiple cancers. Molecular bioSystems, 11(8), 2227-2237 (2015) doi:10.1.039/c5mb00257e

121. J. Xu, C. X. Li, Y. S. Li, J. Y. Lv, Y. Ma, T. T. Shao, L. D. Xu, Y. Y. Wang, L. Du, Y. P. Zhang, W. Jiang, C. Q. Li, Y. Xiao and X. Li: MiRNA-miRNA synergistic network: construction via co-regulating functional modules and disease miRNA topological features. Nucleic Acids Research, 39(3), 825-836 (2011) doi:10.1.093/nar/gkq832

122. A. F. Olena and J. G. Patton: Genomic organization of microRNAs. Journal of Cellular Physiology, n/a-n/a (2009) doi:10.1.002/jcp.21993

123. X. Yuan, C. Liu, P. Yang, S. He, Q. Liao, S. Kang and Y. Zhao: Clustered microRNAs' coordination in regulating proteinprotein interaction network. BMC systems biology, 3, 65 (2009) doi:10.1.186/1752-0509-3-65

124. J. Hausser and M. Zavolan: Identification and consequences of miRNA-target interactions — beyond repression of gene expression. Nature Reviews Genetics, 15(9), 599-612 (2014) doi:10.1.038/nrg3765

125. T. A. Farazi, H. M. Horlings, J. J. ten Hoeve, A. Mihailovic, H. Halfwerk, P. Morozov, M. Brown, M. Hafner, F. Reyal, M. van Kouwenhove, B. Kreike, D. Sie, V. Hovestadt, L. F. A. Wessels, M. J. van de Vijver and T. Tuschl: MicroRNA Sequence and Expression Analysis in Breast Tumors by Deep Sequencing. Cancer Research, 71(13), 4443-4453 (2011) doi:10.1.158/00085472.CAN-11-0608

126. S. V. Laddha, S. Nayak, D. Paul, R. Reddy, C. Sharma, P. Jha, M. Hariharan, A. Agrawal, S. Chowdhury, C. Sarkar and A. Mukhopadhyay: Genome-wide analysis reveals downregulation of miR-379/miR-656 cluster in human cancers. Biology Direct, 8(1) (2013) doi:10.1.186/1745-6150-8-10

127. S. I. Rothschild: microRNA therapies in cancer. Molecular and Cellular Therapies, 2(1), 7 (2014) doi:10.1.186/2052-8426$2-7$

Key Words: miRNA, microRNA, tool, systems biology, biomarkers, computational biology, cancer, Review

Send correspondence to: Laura Cantini, Institut Curie, INSERM U900, PSL Research University, Mines ParisTech, 26, rue d’Ulm, F-75248 Paris, France , Tel: +33 0156246945, E-mail: laura.cantini@curie.fr 
Figure 1. Summary of the main computational modules employed. Summary of the main computational tasks performed by the six chategories of algorithms presented in the paper. The grid reports on the rows the six tool chategories ( (i) Methods based on miRNA expression data; (ii) Methods based on mRNA expression data; (iii) Methods based on combined miRNA-mRNA expression data; (iv) Methods taking into account the miRNA-TF crosstalk; (v) More recent integrative works considering also other data types; (vi) Methods considering the miRNA-miRNA synergistic effect) and in columns the computational modules (miRNA differential expression analysis, network miRNA-miRNA, survival analysis, functional analysis, mRNA differential expression analysis, miRNA targets prediction, network miRNA-mRNA, TFs activity, miRNA-mRNA correlation computation, integration of other data). A violet square is present in position (i,j) if the computational module $\mathrm{j}$ has been employed in at least one publication of the tool chategory i.

Table 1. Summary of the main discussed tools

\begin{tabular}{|l|l|l|}
\hline Method category & $\begin{array}{l}\text { Main tool available to run discussed in } \\
\text { this review }\end{array}$ & $\begin{array}{l}\text { Main procedures not yet implemented in a tool discussed in this } \\
\text { review }\end{array}$ \\
\hline $\begin{array}{l}\text { (i) Methods based on miRNA expression } \\
\text { data }\end{array}$ & $\begin{array}{l}\text { PROGmiR, SAM, ANOVA, Wilcoxon test, } \\
\text { t-test }\end{array}$ & Volinia et al. (44), Piepoli et al. (41), Zhang et al. (39) \\
\hline $\begin{array}{l}\text { (ii) Methods based on mRNA expression } \\
\text { data }\end{array}$ & $\begin{array}{l}\text { Sigterms, CORONA, MirAc, miR-Path, } \\
\text { CoMeTa }\end{array}$ & \\
\hline $\begin{array}{l}\text { (iii) Methods based on combined miRNA- } \\
\text { mRNA expression data }\end{array}$ & $\begin{array}{l}\text { MAGIA, MMIA, CosMic, } \\
\text { TargetRunningSum, MMRA }\end{array}$ & $\begin{array}{l}\text { Cava } \text { et al. (61), Liu } \text { et al. (66), Sehgal } \text { et al. (89), Hua } \text { et al. (85), } \\
\text { Engstrom } \text { et al. (86), Genovese } \text { et al. (87) }\end{array}$ \\
\hline $\begin{array}{l}\text { (iv) Methods taking into account the } \\
\text { miRNA-TF crostalk }\end{array}$ & $\begin{array}{l}\text { MAGIA2, mirConnX, Gene4x, integraMiR, } \\
\text { Dhio-GemiNI, }\end{array}$ & Ying et al. (96), Samantarrai et al. (97), Yu et al. (99), Sun et al. (107) \\
\hline $\begin{array}{l}\text { (v) More recent integrative works } \\
\text { considering also other data types }\end{array}$ & & $\begin{array}{l}\text { Volinia et al. (113), Rajamani } \text { et al. (114), Yang et al (115), Farazi } \text { et } \\
\text { al. (117), Hamilton } \text { et al. (10) }\end{array}$ \\
\hline $\begin{array}{l}\text { (vi) Methods considering the miRNA- } \\
\text { miRNA synergistic effect }\end{array}$ & mirSRN & Xu et al. (121) \\
\hline
\end{tabular}

The main methods/algorithms/tools discussed in the text are here summarized. On the rows are reported the main six categories of approaches described in the text, while the two columns correspond to tools available to run and procedures not yet implemented in a tool, respectively.

Running title: ???? 


\section{Publication processes}

This galley is provided to you for text correction. Please read this galley with great care and make all necessary text changes. The temporary manuscript number of this document is the number assigned to the galley that you received. This number is also included in the letter of acceptance that you received. List of changes to be made before the galley is submitted for publication is included below. Full details of formatting guideline is available online at http://www.bioscience.org/authors. A temporary manuscript number has been assigned to this manuscript. This number appears at the top of the letter of acceptance and is used to number the galley. Please use this number and name of the managing editor in any future correspondence to the Frontiers in Bioscience until the manuscript is published. The permanent manuscript number will be assigned upon publication of the manuscript. Submission of manuscript for publication entails the following steps:

1. Submission of necessary documents by Email. Please send all the required materials including the galley, doi.doc, forms.doc and figure files (fig1.jpg etc) to the editorial office of the Frontiers in Bioscience (fbs@bioscience.org). Please fill and return the publication forms by placement of name of authors on the copyright page, and selecting a package. Please note that submission of publication packages can be done during online submission of the manuscript.

1.1. Galley. Submit final revised galley. Do not change the manuscript number. Save revised file with the same name assigned to the file that you receive such as (4435.doc).

1.2. DOI.doc. Submit DOI linked references with tabular format and live links. Submit as doi.doc (do not use any other filename).

1.3. Figures. Submit final figures. Submit figures as jpg files named fig1, fig2 etc. Do not use any other style such as Fig1 or Fig 1 etc.

1.4. Publication forms. Publication forms including copyright and publication packages.

\subsection{Properly formatted galley}

Text. Please note that all manuscripts should have flawless English and should be free of spelling and scientific errors. Tables and figure legends (not figures) should be placed at the end of the manuscript.

- $\quad$ Change non-English characters to their English correlates in the title, abstract, names or affiliations.

Authors. Format per FBS style. No non-English characters. Provide full first and last name

\begin{tabular}{|l|l|l|l|}
\hline First Name & Middle Name & Last Name & Affiliation \\
\hline & & & \\
\hline & & & \\
\hline & & & \\
\hline & & & \\
\hline & & & \\
\hline & & & \\
\hline & & & \\
\hline & & & \\
\hline & & & \\
\hline
\end{tabular}

Affiliations. Format per FBS style. No non-English characters

Title: Provide a title less than 75 characters with spaces.

Abstract. Format per FBS style. No non-English characters. Please reduce the number of words in the abstract to less than 175 words. 
References. Format per FBS style. Do not use automatic numbering of Word for references. All references should be numbered manually. Follow the following style for references. All references must be justified to right and left and there should be hard return between references as follows.

1. Bart Karl, Peter Thomas: Molecular and cellular adaptation of muscle in response to exercise. Physiol Rev 23, 520535 (1995)

2. Bart Marks, Peter Goll. Skeletal muscle adaptability: significance for metabolism and performance. In: Handbook of Physiology, Sect 10 Skeletal muscle. Eds: LD Peachey, RH Norbert, SR Finn Bethesda, Maryland (1981)

or

1. B Karl, P Thomas: Molecular and cellular adaptation of muscle in response to exercise. Physiol Rev 23, $520-535$ (1995)

2. B Marks, P Goll. Skeletal muscle adaptability: significance for metabolism and performance. In: Handbook of Physiology, Sect 10 Skeletal muscle. Eds: LD Peachey, RH Norbert, SR Finn Bethesda, Maryland (1981)

- Remove all doi ref from this document. DOI with live links to be provided in a separate document as detailed below

Key Words. Provide

Running title. Provide a running title less than 55 characters. See sample (Running title: Production and reduction of ROS)

\subsection{Figure files}

Figures. Provide per FBS style. Figures should be of high quality and $>300$ dpi. Crop the figure close to the image so that no white space around any figure is visible. Place multipart figures in a single file. Place labels in the left lower corner of each figure. Figures that do not follow the above guidelines can not be used for document processing.

Submit as fig1 as jpg file (.jpg is an extension of the file and not part of the name of the file), etc. Do not use any other filename such as fig 1 or Fig1 or Fig 1 etc. Do not include filename or any other name or any white or unused spaces around figure.

\subsection{DOI references with live links}

DOI linked references provided within a file named doi.doc. All doi linked references must have live links. Do not paste data as text. Paste in native format to maintain the links. Live links will lead to conversion of the cursor to a hand. See sample below. Place cursor over doi:10.1002/ijc.20631 and you will note the cursor changes to a hand. All doi in the ref list must have similar live links. Follow the steps provided below to obtain the doi with live links. Some references may not have doi. Please disregard such results. Such references will be followed by a statement such as (doi not found). Please do not remove such references from the list.

1. Go to http://www.crossref.org/

2. Click on "simple text query" in the left column of the page

3. Copy about 50 references at a time from the referfence list

4. Paste the references into the query box

5. Click "submit" button

6. The doi linked references will be displayed in about 30 seconds on the screen

7. Copy all the references including those that do not have live doi links by pressing "Control+C"

8. Paste the data into a blank new document

9. Repeat this process for other references

10. Save the file as doi.doc. Do not add any other text to the page (such as DOI references etc)

A reference sample with live doi.links is shown below

K Almholt, LR Lund, J Rygaard, BS Nielsen, K Danø, J Rømer, M Johnsen: Reduced metastasis of transgenic mammary cancer in urokinase-deficient mice. Int J Cancer 113 (4), 525-32 (2005).

doi:10.1002/ijc.20631 


\subsection{Publication forms}

Invited Review: If your manuscript is an invited review, the basic publication charge for your manuscript is waived. Please choose the "Basic Package" in the order forms if you do not wish to receive a professional galley, reprint, PDF or subscription. Each package includes a series of options including professional galley, reprint, PDF and subscription as specified in the publication forms. Professional galley has a rich two column format with figures and tables inserted in the page where they are cited. As part of any of these packages, you will also receive a PDF file with a license for distribution. Please note that the published online documents do not carry such a license. Some packages also include hard copy reprints and subscription. If you would like to choose any of these packages, please mark them in the order and invoice forms.All these packages have reduced fees for invited reviews.

\section{Acknowledgements by the corresponding author}

I am the corresponding author of this manuscript and I acknowledge that

1. I have read this galley and have made all necessary text changes

2. I approve the publication of this galley without any further text changes.

3. If I wish to request any further changes not included in this galley, I will submit the reprocessing form (http://www.bioscience.org/authors).

Place your name here: [ Click and type ]

Place your E-mail here: [ Click and type ]

Place date here: [ Click and type]

\section{Manuscript Type: Invited review}

Managing Editor: Isabella Castiglioni, Claudia Cava, Gloria Bertoli 